for Euratom does provide for the transfer of Euratom staff to national laboratories is in this sense an advantage. In the period between now and April, when the European Commission is required further to define the research programme, and in the two years between now and the next review of the programme, urgent steps should be taken to see that schemes like this are thoroughly explored.

\section{Pipeline in Trouble}

THE chance that the United States will be able to reap the benefits of the vast oilfields on the North Slope of Alaska continues to recede. A week ago, the United States Appeals Court astonished all parties to the project to build a pipeline from the North Slope to Prudhoe Bay - the consortium of petroleum companies, the disputant environmental groups and no doubt the US Department of the Interior as well-by ruling that the department has no authority to grant a permanent right of way across federal lands to those who would have to service any pipeline that might be built. It is, of course, astounding that the Department of the Interior should have been caught out on a technical legality like this. The result will be that if the department can summon up the nerve, Congress will have to be invited to change the law, in circumstances in which it will be impossible to separate the strictly legal argument from the wider environmental arguments which have bedevilled the Alaskan pipeline almost from the start. Although it is quite fair that complainants should have protested, at the beginning, that the petroleum companies were willing to push ahead with the pipeline project with only scant concern for environmental considerations, more recently it would have been more proper to complain that the Department of the Interior has been a pusillanimous arbitrator in the dispute, and reprehensibly slow to give a lead.

What should it now be urging? The legal argument quite apart, the urgent need is for the department to decide just what contribution the North Slope can be expected to make to the supply of energy in the United States. And if, three years ago, the department's opinion on the virtues of the pipeline project was evenly balanced-the more charitable interpretation of its equivocation - the recognition of the petroleum shortage in the past six months must surely have tipped the balance in favour of exploitation. Surely it will be a strange situation if the United States now shoulders the burden of paying up to $\$ 50,000$ million a year for imports of oil from the Middle East and at the same time decides to leave the petroleum beneath the North Slope where it is. It will be stranger still if the United States permits an increase in the price of petroleum, which could easily double in the next few years, while imposing on itself a self-denying ordinance where Alaskan oil is concerned. Nobody will pretend that the environmental arguments against the Alaskan pipeline should be brushed aside, but at some point in the next few months the United States will have to recognize that some at least of what it now calls the energy crisis is the price which it has chosen to pay for leaving Alaskan oil alone.

At the same time, the United States must somehow come to grips with the problem of putting a value on the environmental qualities which it has come to revere. A part of the argument against the pipeline is that it will permanently disturb a unique ecological system, and that is a point that does require further investigation and consideration. At the same time, a part of the United States environment to which many American voters are attached is that part of the social fabric which provides them with warmth in the winter, air-conditioning in the summer and the power needed to keep American industry in being. An accurate decision about the Alaskan pipeline requires not merely that there should be an investigation of what the environmental damage will be, but an open public discussion about the damage should be weighed against the cost either of importing fuel from the Middle East or of doing without it. Unhappily, there is no real assurance that Congress will be the right forum for making this choice.

\section{Years Ago}

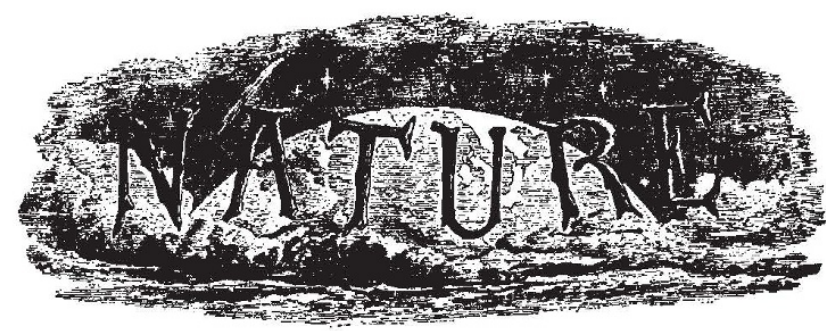

Inherited Feeling

THE remarkable case of an inherited feeling of dislike for a special class of persons, communicated by $\mathrm{Mr}$. Darwin, appears to me to support a view I have long held (but not yet published) as to the explanation of another class of so-called instincts. The three separate instances given in which the dogs showed a violent antipathy to butchers, either without seeing them or when they were dressed as gentlemen, clearly indicates that it was through the sense of smell that the painful sensation was experienced ; and this is quite in accordance with the wonderful delicacy and importance of this sense in most animals, and especially in dogs. It is natural to suppose that some ancestor of these dogs was systematically and cruelly ill-treated by several butchers, perhaps from some thievish propensity or other bad habit which required frequent punishment, so that the smell of a butcher came to be invariably associated with pain and a desire for revenge. But the most important fact to observe is, that there must be some peculiar odour developed in human beings by constant contact with flesh, which a dog can recognise apart from individual peculiarities and in spite of perfect disguise. Now the power many animals possess to find their way back over a road they have travelled blindfolded (shut up in a basket inside a coach for example) has generally been considered to be an undoubted case of true instinct. But it seems to me that an animal so circumstanced will have its attention necessarily active, owing to its desire to get out of its confinement, and that by means of its most acute and only available sense it will take note of the suc. sessive odours of the $w$ ay, which will leave on its mind a series of images as distinc: and prominent as those we should receive by the sense of sight. The recurrence of these odours in their proper inverse order-every house, ditch, field, and village having its own well-marked individuality-would make it an easy matter for the animal in question to follow the identical route back, however many turnings and cross-roads it may have followed. This explanation appears to me to cover almost all the well-authenticated cases of this kind.

$$
\text { Alfred R. Waliace }
$$

I HAVE a cat, of a long.haired breed, whose aversion to dogs is unusually strong. Last autumn, six kittens of hers, under two days old, were in a corner of the kitchen where they had had no opportunity of making acquaintance with any dog; yet, on being stroked (in their mo:her's a'ssence) by a hand which a dog had just licked, more than one of them "swore" violently. This was repeated several times, but the little creatures shored no dislike to being touched with a clean hand.

A Lover of inimals 